\title{
Can high serum anti-Müllerian hormone levels predict the phenotypes of polycystic ovary syndrome (PCOS) and metabolic disturbances in PCOS patients?
}

\author{
Yu Im Hwang, Na Young Sung, Hwa Seon Koo, Sun Hwa Cha, Chan Woo Park, Jin Yeong Kim, Kwang Moon Yang, In Ok Song, \\ Mi Kyoung Koong, Inn Soo Kang, Hye Ok Kim
}

Division of Reproductive Endocrinology and Infertility, Department of Obstetrics and Gynecology, Cheil General Hospital and Women's Healthcare Center, Kwandong University College of Medicine, Seoul, Korea

Objective: To evaluate correlations between serum anti-Müllerian hormone (AMH) levels, phenotypes of polycystic ovary syndrome (PCOS), obesity, and metabolic parameters in patients with PCOS.

Methods: A total of 175 patients with PCOS were diagnosed according to the Rotterdam Consensus were included. Exclusion criteria were age over 40, FSH $>25 \mathrm{mlU} / \mathrm{mL}$, and 17a-OHP $>1.5 \mathrm{ng} / \mathrm{mL}$. The Phenotypes of PCOS were divided into a severe form (oligo-anovulation, ANOV/ hyperandrogenism/polycystic ovary morphology [PCOM]; $n=59$ ) and a mild form without HA (ANOV/PCOM, $n=105$ ). The serum AMH levels were classified into 3 groups ( $<5$ vs. $5-10$ vs. $>10 \mathrm{ng} / \mathrm{mL}$ ). Obesity was defined as body mass index (BMI) $\geq 25 \mathrm{~kg} / \mathrm{m}^{2}(\mathrm{n}=34)$.

Results: The mean age was $25.9 \pm 5.7$ year and mean AMH level was $10.1 \pm 5.4 \mathrm{ng} / \mathrm{mL}$. The BMI $\left(\mathrm{kg} / \mathrm{m}^{2}\right)$ was higher in group $1(24.2 \pm 6.3)$ than in group $2(21.9 \pm 4.3, p=0.046)$ or group $3(21.6 \pm 3.3, p=0.019)$. There was no difference among the three groups in age, menstrual interval, antral follicle counts, androgens, or other metabolic parameters. The obesity group showed significantly lower AMH $(7.7 \pm 3.9 \mathrm{ng} / \mathrm{mL}$ vs. $10.7 \pm 5.6 \mathrm{ng} / \mathrm{mL}), p=0.004)$ and low-density lipoprotein levels $(93.1 \pm 21.2 \mathrm{mg} / \mathrm{dL}$ vs. $107.5 \pm 39.3 \mathrm{mg} / \mathrm{dL}, p=0.031)$, and showed higher total $\mathrm{T}(0.74 \pm 0.59 \mathrm{ng} / \mathrm{mL}$ vs. $0.47 \pm 0.36 \mathrm{ng} / \mathrm{mL}, p=0.001)$, free $\mathrm{T}(2.01 \pm 1.9 \mathrm{vs} .1 .04 \pm 0.8 \mathrm{pg} / \mathrm{mL}, p=0.0001)$, and free androgen index $(6.2 \pm 7.9 \mathrm{vs}$. $3.5 \pm 3.0, p=0.003)$. After controlling for age factors and BMl, the serum AMH levles did not show any significant correlations with other hormonal or metabolic parmeters.

Conclusion: For PCOS patients under the age 40, serum AMH is not negatively correlated with age. High serum AMH levels can not predict the phenotype of PCOS and metabolic disturbances in PCOS patients in the non-obese group. Further study might be needed to define the relation more clearly.

Keywords: Polycystic ovary syndrome; Anti-Mullerian hormone; Hyperandrogenism; Obesity; Age

\section{Introduction}

Polycystic ovary syndrome (PCOS) is the most common endocrine

Received: Jul 19, 2013 · Revised: Sep 11, 2013 · Accepted: Sep 26, 2013 Corresponding author: Hye Ok Kim

Department of Obstetrics and Gynecology, Cheil General Hospital and Women's Health Care Center, Kwandong University College of Medicine, 17 Seoae-ro 1-gil, Jung-gu, Seoul 100-380, Korea

Tel: +82-2-2000-7549 Fax:+82-2-2000-7790 E-mail: ok58163@hanmail.net

This is an Open Access article distributed under the terms of the Creative Commons Attribution Non-Commercial License (http://creativecommons.org/licenses/by-nc/3.0/) which permits unrestricted non-commercial use, distribution, and reproduction in any medium, provided the original work is properly cited. derangement, affecting up to $6 \%$ to $10 \%$ of reproductive-age women [1]. It is characterized by menstrual irregularity, androgen excess, polycystic ovaries and disturbances in glucose metabolism [2]. Insulin resistance is pathophysiologically implicated in reproductive and metabolic abnormalities in PCOS [3]. Dyslipidemia is a common aberration in PCOS. The atherogenic lipid profile including low-density lipoprotein cholesterol (LDL-C) and triglycerides (TGs) and decreased high-density lipoprotein cholesterol (HDL-C) levels are associated with PCOS [4]. According to the Rotterdam 2003 consensus [5], PCOS has been characterized by at least two out of the following three criteria: oligo- or anovulation, clinical or biochemical hyperandrogen- 
ism, and polycystic ovaries on ultrasound. Recently, serum anti-Müllerian hormone (AMH) has emerged as a novel marker for ovarian function. AMH, also termed Müllerian inhibiting substance, is a member of the transforming growth factor- $\beta$ superfamily of glycoprotein [6]. AMH has been found to play an important role in excessive early follicular growth. It also plays a key role in the preventing selection of one follicle from the increased pool and its further maturation to a dominant follicle (follicular arrest) [7] by inhibiting the initial recruitment of primordial follicles [8] and promoting follicular arrest [9]. A high serum AMH level is correlated with an excessive antral follicle count (AFC). However, it is uncertain whether serum AMH levels can predict the phenotypes of polycystic ovary syndrome and metabolic disturbances. Therefore, we investigated whether serum AMH levels could predict the phenotypes of PCOS and metabolic disturbances in PCOS patients.

\section{Methods}

\section{Study population}

We retrospectively evaluated a total of 175 women with PCOS. Data were obtained from a data base including clinical, hormonal, and ultrasound characteristics and data were consecutively recorded between January and September 2011. PCOS was diagnosed according to the criteria from the Rotterdam Consensus of 2003. The entire group of PCOS women were divided into two groups according to their phenotypes. PCOS women with all three diagnostic criteria (oligoanovulation, ANOV/hyperandrogenism, HA/polycystic ovary morphology [PCOM], $n=59$ ) were considered to have the severe form, and those wihout hyperandrogenism (ANOV/PCOM, $n=105$ ), the mild form. There were 11 PCOS patients who satisfied only two categories (ANOV/HA, $n=3 ; \mathrm{HA} / \mathrm{PCOM}, \mathrm{n}=8$ ). These 11 patients were excluded to clarify the effect of hyperandrogenism. The women with PCOS were classified into 3 groups according to their serum AMH level; group $1(<5 \mathrm{ng} / \mathrm{mL}, \mathrm{n}=28)$, group $2(5-10 \mathrm{ng} / \mathrm{mL}, \mathrm{n}=73)$, and group 3 ( $>10 \mathrm{ng} / \mathrm{mL}, \mathrm{n}=74$ ). Obesity was defined as a body mass index $(\mathrm{BMI}) \geq 25 \mathrm{~kg} / \mathrm{m}^{2}(\mathrm{n}=34)$. The exclusion criteria were age over 40 year, $\mathrm{FSH}>25 \mathrm{mlU} / \mathrm{mL}$, and $17 \mathrm{a}-\mathrm{OH}-\mathrm{P}>1.5 \mathrm{ng} / \mathrm{mL}$.

\section{Hormonal assays}

On day 2 to 3 of a spontaneous menstrual cycle, the blood samples for the various parameters including anti-müllerian hormone (AMH), $\mathrm{LH}, \mathrm{FSH}, \mathrm{T}$, free testosterone (fT), sex hormone binding globulin (SHBG), free androgen index, dehydroepiandrosterone (DHEAS), homeostasis model of assessment-insulin resistance (HOMA-IR), glycosylated hemoglobin (HbA1c), cholesterol, triglyceride, low-density lipoprotein (LDL), high-density lipoprotein (HDL) and high sensitivity c-active protein (hs-CRP) were obtained by venous puncture. The serum AMH level was measured by commercial enzyme-linked immunoassay (Immunotech version, Beckman Coulter, Marseille, France).

\section{Statistical analysis}

Statistical analyses were performed with SPSS ver. 12.0 (SPSS Inc., Chicago, IL, USA). To determine the correlation between AMH and the other variables, the Spearman coefficient was calculated. Each variable was presented as mean $\pm S D$. A $p$-value $<0.05$ was considered statistically significant.

\section{Results}

\section{Serum AMH levels in PCOS patients according to the age}

The mean age of the 175 PCOS women was $25.9 \pm 5.7$ years and the mean AMH level was $10.1 \pm 5.4 \mathrm{ng} / \mathrm{mL}$. The distribution of AMH concentrations in women with PCOS was quite different from that in women with regular menstruation, as has been previously reported by Yoo et al. [10]. The mean serum AMH levels of 1,298 women (mean age, $34.4 \pm 0.1$ year) with regular menstruation was $3.6 \pm 0.1 \mathrm{ng} / \mathrm{mL}$ and decreased with age (Figure $1 \mathrm{~A}$ ).

This study showed that the PCOS patients had 2.8 fold higher serum AMH levels than those of the normo-ovulatory patients. We divided the study population into 5 categories: $\leq 20$ year $(n=37), 21$ 25 year $(n=41), 26-30$ year $(n=53), 31-35$ year $(n=37), 36-40$ year $(n=7)$. The median values of the AMH according to the age group in the PCOS women were somewhat maintained until the age of 35 . There was no significant difference in AMH levels according to age (Figure 1B).

\section{Basal characteristics, androgen, and metabolic parameters according to serum AMH levels}

The basic characteristics, androgen and metabolic parameters are presented and compared according to the the serum AMH levels in Table 1. The serum AMH levels were categorized into 3 groups: group $1(<5 \mathrm{ng} / \mathrm{mL})$, group $2(5-10 \mathrm{ng} / \mathrm{mL})$, and group $3(>10 \mathrm{ng} / \mathrm{mL})$. The mean age did not differ among 3 groups. The BMI $\left(\mathrm{kg} / \mathrm{m}^{2}\right)$ was the only parameter that was differed significantly and it was higher in low AMH group $1(24.2 \pm 6.3)$ than in group $2(21.9 \pm 4.3, p=0.046)$ or group $3(21.6 \pm 3.3, p=0.019)$. There were no significant differences in the other parameters of age, menstrual interval, AFC, F-G score, total $\mathrm{T}$, free T, SHBG, free androgen index (FAI), DHEAS, cholesterol, triglyceride, HDL, LDL, HOMA-IR, LH, FSH, LH/FSH ratio, TSH, PRL, hs $\mathrm{CRP}$, or $\mathrm{HbA1c}$ ) among the $3 \mathrm{AMH}$ groups. After controlling age factor and $\mathrm{BMI}$, serum AMH levels did not show any significant correlations with other hormonal or metabolic parameters. However, in total, the AMH level showed a negative correlation with free $\mathrm{T}(\mathrm{r}=-0.153, p=$ $0.049)$ and $17-\mathrm{OHP}(r=-0.262, p=0.002)$. 

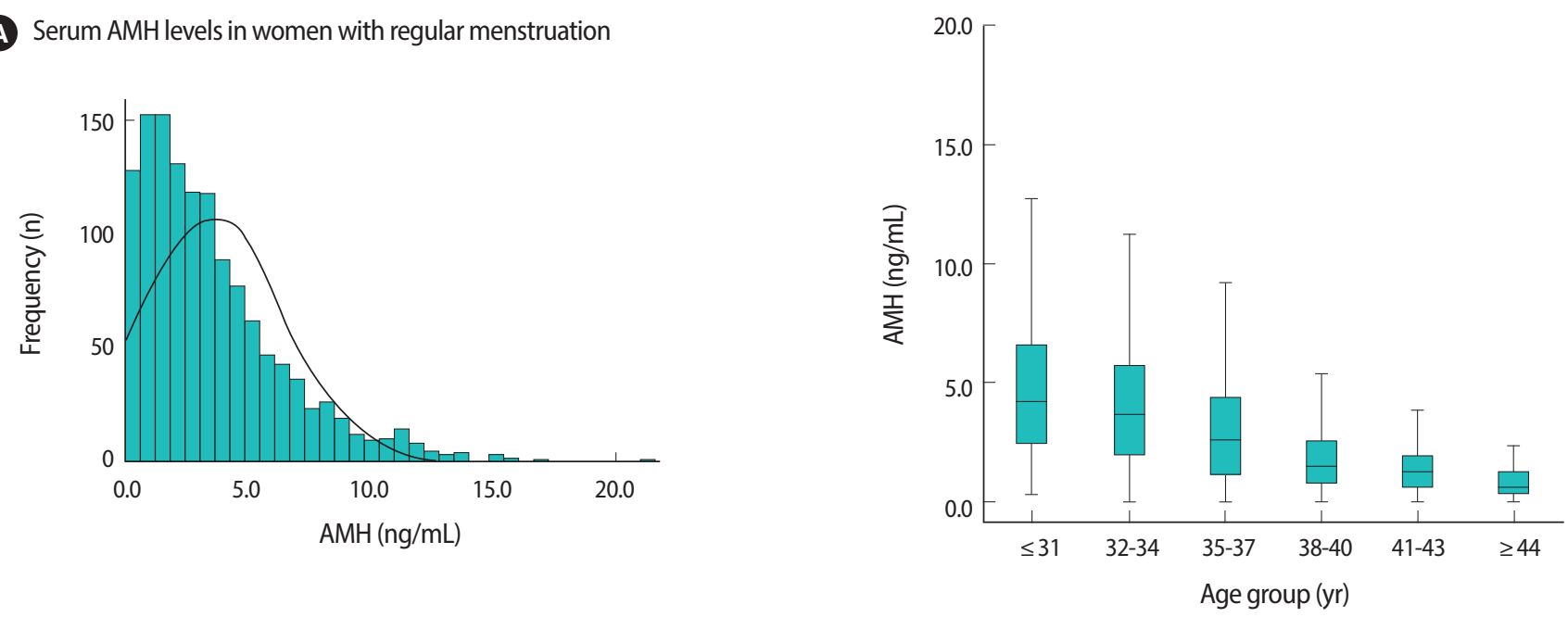

B Serum AMH levels in PCOS patients
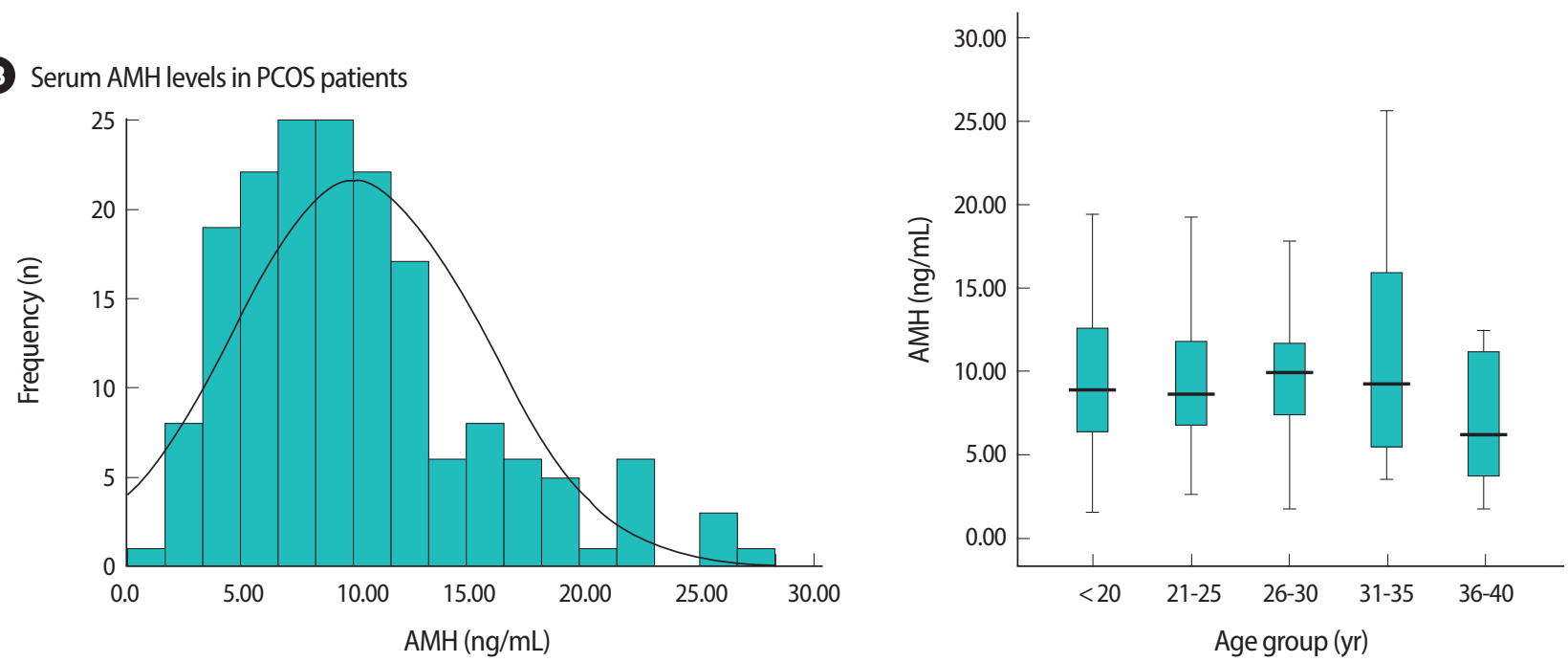

Figure 1. The frequency of serum AMH levels and serum AMH levels according to age group in women with regular menstruation (A) and $P C O S$ (B). (A) In women with regular menstruation (Adapted from Yoo et al. Clin Exp Reprod Med 2011;38:93-7 [10]). (B) In women with PCOS (in present study). PCOS, polycystic ovary syndrome; $\mathrm{AMH}$, anti-Müllerian hormone.

\section{Serum AMH levels, androgen and metabolic parameters according to BMI}

The women were classified into two groups according to their BMI either $<25 \mathrm{~kg} / \mathrm{m}^{2}$ or $\geq 25 \mathrm{~kg} / \mathrm{m}^{2}$. The obese group showed a significantly lower AMH level $(7.7 \pm 3.9 \mathrm{ng} / \mathrm{mL}$ vs. $10.7 \pm 5.6 \mathrm{ng} / \mathrm{mL}, p=0.004)$, total cholesterol ( $191.5 \pm 33.6 \mathrm{mg} / \mathrm{dL}$ vs. $174.4 \pm 25.7 \mathrm{mg} / \mathrm{dL}, p=0.019)$ and LDL cholesterol level (107.5 \pm 39.3 vs. $93.1 \pm 21.2 \mathrm{mg} / \mathrm{dL}, p=0.031)$ (Table 2). On the other hand, the total T $(0.74 \pm 0.59 \mathrm{ng} / \mathrm{mL}$ vs. $0.47 \pm$ $0.36 \mathrm{ng} / \mathrm{mL}, p=0.001)$, free $\mathrm{T}(2.01 \pm 1.9 \mathrm{pg} / \mathrm{mL}$ vs. $1.04 \pm 0.8 \mathrm{pg} / \mathrm{mL}$, $p=0.0001), \operatorname{FAl}(6.2 \pm 7.9$ vs. $3.5 \pm 3.0, p=0.003)$ and DHEAS (194.8 \pm $75.3 \mu \mathrm{g} / \mathrm{dL}$ vs. $238.7 \pm 76.8 \mu \mathrm{g} / \mathrm{dL}, p=0.05)$ were higher in the obese group. The correlationship between $\mathrm{AMH}$ and other metabolic parameters was also evaluated in two groups each (Figure 2). In nonobese group with a BMl $<25 \mathrm{~kg} / \mathrm{m}^{2}$, there was no statistically signifi- cant relationship between $\mathrm{AMH}$ and the other parameters. On the other hand, in the obese group, $\mathrm{AMH}$ was significantly negatively correlated with $\mathrm{BMI}, 17-\mathrm{OH}$ progesterone and free testosterone. $\mathrm{AMH}$ also had a negative correlation with parameters associated with hyperandrogenism, but for these relationships, there were no statistical significance.

\section{Serum AMH levles, and metabolic parameters according to hyperandrogenism}

The entire group of PCOS women were divided into two groups according to their phenotype (severe form vs. mild form). About one third of this study population had PCOS with hyperandrogenism. There was no significant differences in serum AMH levels, AFC, cholesterol, triglyceride, $\mathrm{HDL}$, LDL, HOMA-IR, LH, FSH, or the LH/FSH ratio 
Table 1. Androgen and metabolic parameters in patients with PCOS according to the serum AMH levels

\begin{tabular}{|c|c|c|c|c|}
\hline \multirow{2}{*}{ Characteristic } & \multicolumn{3}{|c|}{ Serum AMH levels ( $\mathrm{ng} / \mathrm{mL}$ ) } & \multirow{2}{*}{$p$-value } \\
\hline & $<5$ & $5-10$ & $>10$ & \\
\hline $\mathrm{N}(\%)$ & $28(16)$ & $73(41.7)$ & $74(42.3)$ & - \\
\hline Age (yr) & $26.6 \pm 6.6$ & $25.6 \pm 5.6$ & $26.0 \pm 5.5$ & NS \\
\hline $\mathrm{BMI}\left(\mathrm{kg} / \mathrm{m}^{2}\right)$ & $24.2 \pm 6.3$ & $21.9 \pm 4.3$ & $21.6 \pm 3.3$ & 0.019 \\
\hline Menstrual interval (day) & $128.9 \pm 107$ & $114.5 \pm 91.7$ & $98.6 \pm 76.4$ & NS \\
\hline Antral follicle counts & $19.9 \pm 5.5$ & $18.2 \pm 5.6$ & $17.5 \pm 5.3$ & NS \\
\hline LH/FSH ratio & $2.4 \pm 2.9$ & $1.9 \pm 0.9$ & $2.1 \pm 1.4$ & NS \\
\hline Testosterone $(\mathrm{ng} / \mathrm{mL})$ & $0.61 \pm 0.7$ & $0.52 \pm 0.4$ & $0.51 \pm 0.4$ & NS \\
\hline Free testosterone $(\mathrm{pg} / \mathrm{mL})$ & $1.56 \pm 1.8$ & $1.41 \pm 1.2$ & $0.99 \pm 0.8$ & NS \\
\hline SHBG (nmol/L) & $73.8 \pm 53.2$ & $71.1 \pm 45.7$ & $68.4 \pm 50.0$ & NS \\
\hline Free androgen index & $5.17 \pm 8.9$ & $3.81 \pm 3.0$ & $4.05 \pm 3.5$ & NS \\
\hline DHEAS ( $\mu \mathrm{g} / \mathrm{dL})$ & $200.1 \pm 81.4$ & $195.2 \pm 80.7$ & $212.0 \pm 71.9$ & NS \\
\hline HOMA-IR & $5.5 \pm 7.7$ & $4.8 \pm 5.9$ & $5.3 \pm 6.6$ & NS \\
\hline $\mathrm{HbA1c}(\%)$ & $5.2 \pm 0.3$ & $5.3 \pm 0.3$ & $5.8 \pm 1.4$ & NS \\
\hline Cholesterol (mg/dL) & $188.5 \pm 30.7$ & $181.7 \pm 31.9$ & $190.9 \pm 34.1$ & NS \\
\hline Triglyceride (mg/dL) & $110.7 \pm 77.5$ & $103.7 \pm 53.3$ & $102.8 \pm 70.9$ & NS \\
\hline $\mathrm{LDL}(\mathrm{mg} / \mathrm{dL})$ & $99.7 \pm 21.1$ & $100.6 \pm 30.0$ & $107.6 \pm 28.4$ & NS \\
\hline $\mathrm{HDL}(\mathrm{mg} / \mathrm{dL})$ & $61.3 \pm 15.9$ & $59.3 \pm 14.8$ & $62.7 \pm 14.5$ & NS \\
\hline $\mathrm{hsCRP}(\mathrm{mg} / \mathrm{dL})$ & $1.4 \pm 1.9$ & $0.8 \pm 1.2$ & $1.3 \pm 1.7$ & NS \\
\hline
\end{tabular}

Values are presented as number (\%) or mean \pm SD; $p$-value $<0.05$, statistical significant.

PCOS, polycystic ovary syndrome; AMH, anti-Müllerian hormone; NS, not significant; BMI, body mass index; SHBG, sex hormone binding globulin; DHEAS, dehydroepiandrosterone-sulfate; HOMA-IR, homeostasis model assessment for insulin resistance index; HbA1c, glycosylated hemoglobin; LDL, low-density lipoprotein; HDL, high-density lipoprotein; $\mathrm{hs-CRP,} \mathrm{high} \mathrm{sensitivity} \mathrm{C-reactive} \mathrm{protein.}$

Table 2. Serum AMH levels, androgen, and metabolic parameters in PCOS patients according to BMI

\begin{tabular}{lccc}
\hline \multirow{2}{*}{ Characteristic } & \multicolumn{2}{c}{ Body mass index $\left(\mathrm{kg} / \mathrm{m}^{2}\right)$} & \\
\cline { 2 - 3 } & \multicolumn{2}{c}{$<$-value } \\
\cline { 2 - 3 } $\mathrm{N}(\%)$ & $141(81)$ & $34(19)$ & - \\
Age $(\mathrm{yr})$ & $25.8 \pm 5.5$ & $26.1 \pm 6.7$ & $\mathrm{NS}$ \\
AMH $(\mathrm{ng} / \mathrm{mL})$ & $10.7 \pm 5.6$ & $7.7 \pm 3.9$ & 0.004 \\
LH/FSH ratio & $2.1 \pm 1.6$ & $2.2 \pm 1.0$ & $\mathrm{NS}$ \\
Prolactin $(\mathrm{ng} / \mathrm{mL})$ & $8.8 \pm 5.7$ & $11.3 \pm 7.7$ & 0.037 \\
Testosterone $(\mathrm{ng} / \mathrm{mL})$ & $0.47 \pm 0.4$ & $0.74 \pm 0.6$ & 0.001 \\
Free testosterone $(\mathrm{pg} / \mathrm{mL})$ & $1.04 \pm 0.8$ & $2.09 \pm 1.9$ & 0.0001 \\
Free androgen index & $3.52 \pm 3.0$ & $6.20 \pm 7.9$ & 0.004 \\
DHEAS $(\mu \mathrm{g} / \mathrm{dL})$ & $194.8 \pm 75.3$ & $238.7 \pm 76.8$ & 0.005 \\
HOMA-IR & $4.8 \pm 5.6$ & $6.1 \pm 8.4$ & $\mathrm{NS}$ \\
Cholesterol $(\mathrm{mg} / \mathrm{dL})$ & $191.5 \pm 33.6$ & $174.4 \pm 25.7$ & 0.019 \\
LDL $(\mathrm{mg} / \mathrm{dL})$ & $107.5 \pm 29.3$ & $93.1 \pm 21.2$ & 0.031 \\
\hline
\end{tabular}

Values are presented as number (\%) or mean \pm SD; $p$-value $<0.05$, statistical significant.

PCOS, polycystic ovary syndrome; BMI, body mass index; NS, not significant; $\mathrm{AMH}$, anti-Müllerian hormone; DHEAS, dehydroepiandrosterone-sulfate; HOMA-IR, homeostasis model assessment for insulin resistance index; LDL, low-density lipoprotein.

between the two groups. Only insulin $120^{\prime}(173.1 \pm 299.4 \mu \mathrm{U} / \mathrm{mL}$ vs. $85.8 \pm 63.3 \mu \mathrm{U} / \mathrm{mL}, p=0.03$ ) was significantly higher in PCOS women with the severe form (Table 3 ).

\section{Discussion}

It is already known that AMH levels decrease with age in women with normo-ovulatory cycles. A similar decline was observed in women with PCOS in previous reports, but at a slower reduction rate. In a recent in vitro study, it was found that $\mathrm{AMH}$ production per graulosa cell was increased by up to $75 \%$ in women with PCOS compared with controls [11]. As a result, the AMH was 2- to 3-fold higher and remained elevated until 40 years of age in the PCOS subjects [12]. Also, in present study, the AMH level did not seem to be negatively correlated with age in the PCOS patients under 40 years of age. The serum AMH levels of the PCOS patients were not correlated with antral follicle count in this study.

Pigny et al. [13] found that BMI did not influence the circulating $\mathrm{AMH}$ concentrations in women with PCOS. However, it was observed that obese women of late reproductive age (35-49 years) had significantly lower AMH levels, compared to normal weight women of similar age [14]. There was no statistically significant correlation between BMI and $\mathrm{AMH}$ in the non-obese group in this study. However, in the obese group with a $\mathrm{BMI} \geq 25 \mathrm{~kg} / \mathrm{m}^{2}$, BMl was negatively correlated with $\mathrm{AMH}$ and the relationship was statistically significant. The mechanism underlying this inverse relationship between obesity and AMH is still unclear, but two possible explanations for this relationship have been suggested: 1) obesity is associated with decreased ovarian reserves 

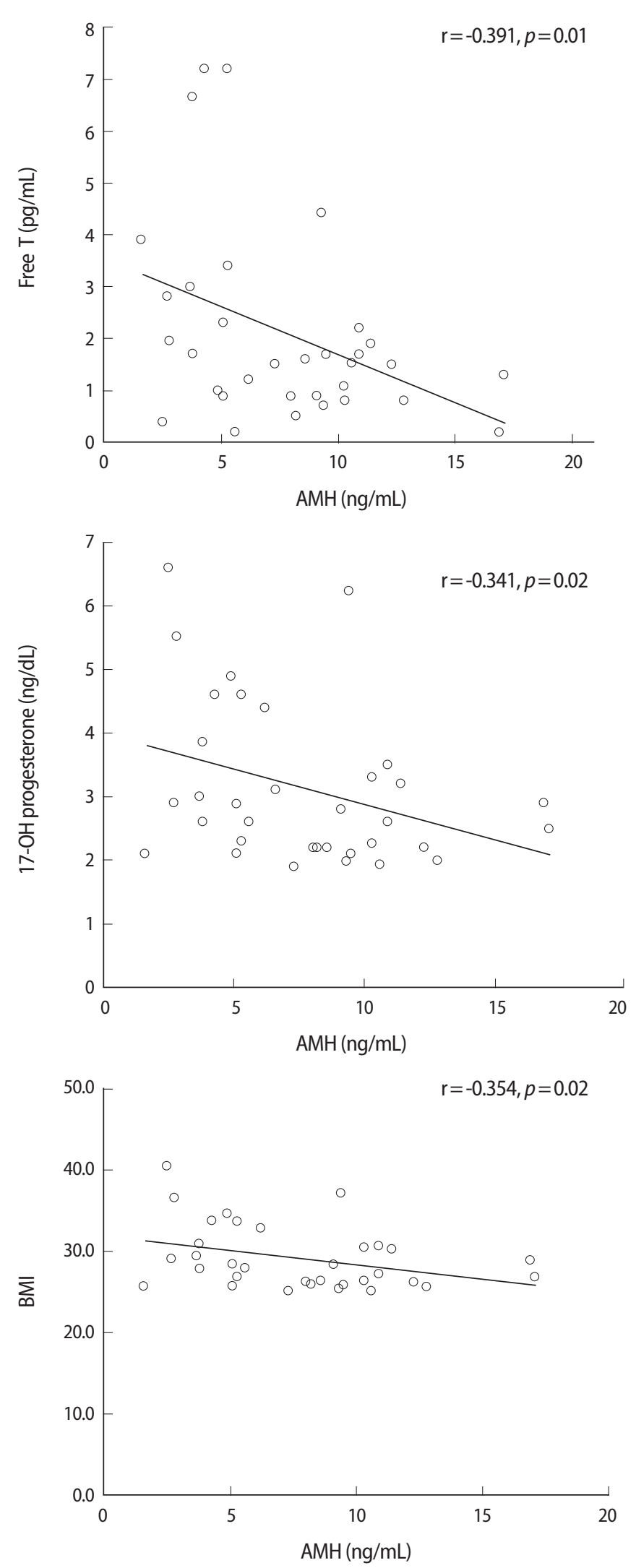

Figure 2. Pearson correlations between $\mathrm{AMH}$ and other parameters in obese PCOS group (BMI $\left.\geq 25 \mathrm{~kg} / \mathrm{m}^{2}\right)$.
Table 3. Serum AMH levels and metabolic parameters according to the phenotypes of PCOS

\begin{tabular}{lccc}
\hline & \multicolumn{2}{c}{ Phenotypes of PCOS } & \\
\cline { 2 - 3 } Characteristic & $\begin{array}{c}\text { Severe type } \\
\text { (ANOV+HA+PCOM) }\end{array}$ & $\begin{array}{c}\text { Mild type } \\
\text { (ANOV+PCOM) }\end{array}$ & \\
\hline $\mathrm{N}(\%)$ & $59(36)$ & $105(64)$ & - \\
Age $(\mathrm{yr})$ & $26.0 \pm 6.1$ & $25.9 \pm 5.6$ & $\mathrm{NS}$ \\
AMH $(\mathrm{ng} / \mathrm{mL})$ & $10.1 \pm 5.7$ & $10.0 \pm 5.5$ & NS \\
BMI $\left(\mathrm{kg} / \mathrm{m}^{2}\right)$ & $23.6 \pm 4.5$ & $21.1 \pm 4.0$ & 0.001 \\
LH/FSH ratio & $2.4 \pm 2.2$ & $1.9 \pm 1.1$ & NS \\
Testosterone $(\mathrm{ng} / \mathrm{mL})$ & $0.83 \pm 0.6$ & $0.35 \pm 0.2$ & 0.0001 \\
Free testosterone $(\mathrm{pg} / \mathrm{mL})$ & $2.01 \pm 1.5$ & $0.73 \pm 0.5$ & 0.0001 \\
SHBG $(\mathrm{nmol} / \mathrm{L})$ & $56.3 \pm 39.4$ & $81.9 \pm 51.7$ & 0.002 \\
Free androgen index & $7.1 \pm 6.5$ & $2.0 \pm 1.3$ & 0.0001 \\
DHEAS $(\mu \mathrm{g} / \mathrm{dL})$ & $248.2 \pm 83.1$ & $178.9 \pm 62.9$ & 0.0001 \\
Insulin $0^{\prime}(\mu \mathrm{U} / \mathrm{mL})$ & $23.8 \pm 33.9$ & $19.2 \pm 18.9$ & NS \\
Insulin $120^{\prime}(\mu \mathrm{U} / \mathrm{mL})$ & $173.1 \pm 299.4$ & $85.8 \pm 63.3$ & 0.033 \\
HOMA-IR & $5.3 \pm 7.2$ & $4.7 \pm 5.4$ & NS \\
\hline
\end{tabular}

Values are presented as number (\%) or mean \pm SD; $p$-value $<0.05$, statistical significant.

PCOS, polycystic ovary syndrome; ANOV, oligo-anovulation; HA, hyperandrogenism; PCOM, polycystic ovary morphology on ultrasound; NS, not significant; $A M H$, anti-Müllerian hormone; BMI, body mass index; SHBG, sex hormone binding globulin; DHEAS, dehydroepiandrosterone-sulfate; HOMA$\mathrm{IR}$, homeostasis model assessment for insulin resistance index.

[15]; or 2) obesity is associated with follicular dysfunction [16]. In the present study, the obese PCOS subjects also showed significantly lower AMH levels $(7.7 \pm 3.9 \mathrm{ng} / \mathrm{mL}$ vs. $10.7 \pm 5.6 \mathrm{ng} / \mathrm{mL}, p=0.004)$, compared with the non-obese PCOS patients.

Androgens have been shown to stimulate early stages of follicular growth and to increase the number of antral follicles in the rat ovary [17]. Previous studies have shown that circulating AMH levels are significantly higher in subjects with PCOS, compared to women with a normal menstrual cycle, and serum AMH levels correlate with circulating androgens [18]. That is because the production of AMH by granulosa cells of PCOS women is increased, and the genes for the AMH, FSH and androgen recepters are overexpressed [19]. In this present study, AMH showed a negative correlation with androgen components but it was not statistically significant in the non-obese group. It was also negatively correlated in the obese group but notably, free testosterone and $17-\mathrm{OH}$ progesterone were significantly inversely correlated.

PCOS is frequently but not consistently associated with insulin resistance (IR) and its compensatory hyperinsulinism (HI) [1]. It is still debated whether IR/HI is intrinsic to the disease or is an optional coexistent factor that acts as a "second hit" to enhance the phenotypic expression of PCOS [20].

You et al. [21] reported that increased serum AMH levels in PCOS are correlated with total testosterone and polycystic ovarian mor- 
phology. Taking all these results into account, high serum AMH levels could not predict the phenotype of PCOS and metabolic disturbances in non-obese PCOS patients in this study. Howevwe, in the obese group, AMH was negatively correlated with $\mathrm{BMI}, 17-\mathrm{OH}$ progesterone and free testosterone. We could not find an explanation for this.

In conclusion, the serum AMH level is not negatively correlated with age for PCOS patients under the age 40 . Moreover, high serum AMH levels could not predict the phenotype of PCOS and metabolic disturbances in PCOS patients in the non obese group. Further research on a larger scale might be needed to clarify the efficacy of serum AMH as a predictor of phenotype and metabolic diturbances in PCOS patients.

\section{Conflict of interest}

No potential conflict of interest relevant to this article was reported.

\section{References}

1. Norman RJ, Dewailly D, Legro RS, Hickey TE. Polycystic ovary syndrome. Lancet 2007;370:685-97.

2. Piltonen T, Morin-Papunen L, Koivunen R, Perheentupa A, Ruokonen A, Tapanainen JS. Serum anti-Mullerian hormone levels remain high until late reproductive age and decrease during metformin therapy in women with polycystic ovary syndrome. Hum Reprod 2005;20:1820-6.

3. Diamanti-Kandarakis E. Polycystic ovarian syndrome: pathophysiology, molecular aspects and clinical implications. Expert Rev Mol Med 2008;10:e3.

4. Diamanti-Kandarakis E, Papavassiliou AG, Kandarakis SA, Chrousos GP. Pathophysiology and types of dyslipidemia in PCOS. Trends Endocrinol Metab 2007;18:280-5.

5. Rotterdam ESHRE/ASRM-Sponsored PCOS consensus workshop group. Revised 2003 consensus on diagnostic criteria and longterm health risks related to polycystic ovary syndrome (PCOS). Hum Reprod 2004;19:41-7.

6. Findlay JK, Drummond AE, Dyson ML, Baillie AJ, Robertson DM, Ethier JF. Recruitment and development of the follicle; the roles of the transforming growth factor-beta superfamily. Mol Cell Endocrinol 2002;191:35-43.

7. Jonard S, Dewailly D. The follicular excess in polycystic ovaries, due to intra-ovarian hyperandrogenism, may be the main culprit for the follicular arrest. Hum Reprod Update 2004;10:107-17.

8. Durlinger AL, Gruijters MJ, Kramer P, Karels B, Ingraham HA, Nachtigal MW, et al. Anti-Mullerian hormone inhibits initiation of primordial follicle growth in the mouse ovary. Endocrinology 2002; 143:1076-84

9. La Marca A, Volpe A. Anti-Mullerian hormone (AMH) in female reproduction: is measurement of circulating $\mathrm{AMH}$ a useful tool? Clin Endocrinol (Oxf) 2006;64:603-10.

10. Yoo JH, Kim HO, Cha SW, Park CW, Yang KM, Song IO, et al. Age specific serum anti-Mullerian hormone levels in 1,298 Korean women with regular menstruation. Clin Exp Reprod Med 2011; 38:93-7.

11. Pellatt L, Hanna L, Brincat M, Galea R, Brain H, Whitehead S, et al. Granulosa cell production of anti-Müllerian hormone is increased in polycystic ovaries. J Clin Endocrinol Metab 2007;92:240-5.

12. Piltonen T, Morin-Papunen L, Koivunen R, Perheentupa A, Ruokonen A, Tapanainen JS. Serum anti-Müllerian hormone levels remain high until late reproductive age and decrease during metformin therapy in women with polycystic ovary syndrome. Hum Reprod 2005;20:1820-6.

13. Pigny P, Merlen E, Robert Y, Cortet-Rudelli C, Decanter C, Jonard S, et al. Elevated serum level of anti-mullerian hormone in patients with polycystic ovary syndrome: relationship to the ovarian follicle excess and to the follicular arrest. J Clin Endocrinol Metab 2003; 88:5957-62

14. Freeman EW, Gracia CR, Sammel MD, Lin H, Lim LC, Strauss JF. Association of anti-mullerian hormone levels with obesity in late reproductive-age women. Fertil Steril 2007;87:101-6.

15. Spandorfer SD, Kump L, Goldschlag D, Brodkin T, Davis OK, Rosenwaks Z. Obesity and in vitro fertilization: negative influences on outcome. J Reprod Med 2004;49:973-7.

16. Hartz AJ, Barboriak PN, Wong A, Katayama KP, Rimm AA. The association of obesity with infertility and related menstural abnormalities in women. Int J Obes 1979;3:57-73.

17. Tetsuka M, Whitelaw PF, Bremner WJ, Millar MR, Smyth CD, Hillier SG. Developmental regulation of androgen receptor in rat ovary. J Endocrinol 1995;145:535-43.

18. Cook CL, Siow Y, Brenner AG, Fallat ME. Relationship between serum mullerian-inhibiting substance and other reproductive hormones in untreated women with polycystic ovary syndrome and normal women. Fertil Steril 2002;77:141-6.

19. Dewailly D, Gronier H, Poncelet E, Robin G, Leroy M, Pigny P, et al. Diagnosis of polycystic ovary syndrome (PCOS): revisiting the threshold values of follicle count on ultrasound and of the serum AMH level for the definition of polycystic ovaries. Hum Reprod 2011;26:3123-9.

20. Thomson RL, Buckley JD, Moran $\sqcup$, Noakes $M$, Clifton PM, Norman $\mathrm{RJ}$, et al. The effect of weight loss on anti-Müllerian hormone levels in overweight and obese women with polycystic ovary syndrome and reproductive impairment. Hum Reprod 2009;24: 1976-81.

21. You SY, Park SY, Yang GY, Jeong KA, Kim YJ, Chung HW. Anti-Mullerian hormone in women with polycystic ovary syndrome. Korean J Obstet Gynecol 2012;55:315-24. 